\title{
Smart classroom environments affect teacher-student interaction: Evidence from a behavioural sequence analysis
}

\author{
Zehui Zhan, Qianyi Wu, Zhihua Lin, Jiayi Cai
}

School of Information Technology in Education, South China Normal University

\begin{abstract}
This study investigated the effect of classroom settings on teacher-student interaction in higher education by comparing the behavioural sequences in smart classrooms (SCs) and traditional multimedia classrooms (TMCs). Twenty in-classroom teaching sessions were randomly selected from six universities in South China, involving 1,043 students and 23 teachers. Half of the sessions were taken in SCs as the experimental group, and half were in TMCs as the control group. A teacher-student interaction behaviour coding schema was developed, and a total of 17,805 observable behaviours were collected and coded sequentially via a review of classroom videos. Then, the behavior pattern diagram was set up to visualise a lag sequential analysis results by four themes, namely teacher-talk, teacher-action, studenttalk and student-action. Results show that compared to TMCs, the SCs triggered significantly more self-initiated student actions and student-driven teacher talk, while teacher-initiated talk decreased significantly, indicating that students' autonomy was strengthened in the SC. Furthermore, teachers' workload was somewhat reduced, and they obtained more support with trying new pedagogies with mobile terminals in the data-rich environment. These findings provide evidence to validate the effect of SCs on increasing teacher-student interaction and strengthening the students' dominant position.
\end{abstract}

Implications for practice or policy:

- We recommend that teachers provide guidance and scaffolding to support students in SCs, especially during the inquiry process.

- Instructional designers should consider more course activities and collect students' feedback during course via smart terminals, to make the learning process more assessable.

- Universities should provide training to help teachers improve their technological, pedagogical and content knowledge, become acquainted with SC infrastructure and provide technical support during class.

Keywords: smart classroom (SC), traditional multimedia classroom (TMC), behavioural sequence, teacher-student interaction, lag sequential analysis (LSA)

\section{Introduction}

With the rapid development of smart technologies, more and more universities have started to build up smart classrooms (SCs) to support teaching and learning. An SC is thought of as the classroom of the future, aiming to optimise the presentation of teaching content, promote the acquisition of learning resources (Selim et al., 2020), improve teacher-student interaction (Akhrif et al., 2020; Jin et al., 2019), help teachers assess student learning (Huang et al., 2012) and take charge of in-classroom teaching (Zhu et al., 2020).

Compared to a traditional multimedia classroom (TMC), the SC is regarded as an updated form (Zhan et al., in press). A TMC is a comprehensive multi-system teaching environment, including a computer system, projection display system, sound reinforcement system and a central control system Kong, 2018), generally equipped with fixed hardware (e.g., teachers' computers, projectors, blackboards and students' fixed desks and chairs) and traditional software (e.g., Microsoft Office Word, Excel, PowerPoint), while an SC is generally equipped with flexible hardware devices (e.g., all-in-one computers, mobile terminals, electronic whiteboards, a virtual reality immersive presentation device, activity desks and movable chairs) and more interactive software with artificial intelligence (e.g., online interactive platforms, learning management systems, face recognition, emotional recognition).

Some scholars believe that smart technologies may help to improve interaction, save experimental cost and extend the limitation of time and space during teaching (Jian \& Hong, 2012). Also, some researchers consider that with smart technologies teachers will be able to choose more suitable ways of teaching (i.e., 
online, face-to-face or blended) to meet different types of needs (Hamiti \& Reka, 2012; Selim et al., 2020; Simelane \& Mji, 2014). However, Shah (2014) holds an opposite view and has claimed that smart technologies are sometimes used incorrectly and may make the learning process more complex, hindering student understanding. This article discusses research on the effect of a smart technology-enhanced classroom environment, focusing on whether an SC really helps implement a student-centered approach during teaching. The purpose of this study was to investigate teacher-student interaction in an SC and compare it with that in a TMC. The findings may encourage teachers and SC designers to evaluate and understand the effectiveness of smart technologies in the teaching and learning process, in order to improve SC design and provide appropriate support to students.

\section{Literature review}

\section{Teacher-student interaction in TMCs}

In-classroom interactions in TMCs can be categorised as teacher-student interaction, student-student interaction and human-computer interaction (L. Wang et al., 2009). Teacher-student interaction is achieved mainly through teacher-student question and answer activities, direct instruction and expert cooperation. Student-student interaction is achieved mainly through group discussions and peer-based evaluation and help. Human-computer interaction refers to the interaction between teachers, students, computers and the environment created by multimedia and the teaching atmosphere.

One of the major advantages of a TMC is that it can increase the information capacity of the classroom (S. H. Fu, 2019; Jia et al., 2014) and make the teaching process more diversified (Cai et al., 2012; Guo \& Zheng, 2012). However, it generates a one-way output of learning content in the form of audiovisual graphics, and teachers must be responsible for the rest of the work, including standing behind the main console and manipulating the computer and managing the teaching process and learner evaluation, which increases the teacher's workload, and hence hinders other forms of communication between teachers and students (Guo \& Zheng, 2012; Rusanganwa, 2013; X. Wang, 2011). Since the learning content is presented in more ways in a TMC compared to traditional classrooms, increased attention to the multimedia presentation shortens the time for the teacher's explanations of the knowledge content. The additional multimedia might also result in redundant resources; and students may not be able to digest the large amount of content in a short time during class (J. Fu, 2011). To this end, some scholars have suggested that effective teacher-student interaction should be meticulously designed, so that teachers' workload is reduced, and they can spend more time on interacting with students (J. Liu et al., 2009).

\section{Teacher-student interaction in SCs}

Different from the traditional combination of "chalk + blackboard" (Zhang et al., 2016, p. 43) and "computer + projection" (Zhang et al., 2016, p. 43), an SC is a new type of classroom that expands the learning space and creates atmosphere through interactive teaching platforms and various media (B. Q. Liu, 2016; Selim et al., 2020). In an SC, students have more opportunities to explore, create, display and evaluate with the support of smart technology. Teachers can also use the technology to present teaching content, detect students' learning status, diagnose the teaching process and adjust their teaching method in a timely way (Zhang et al., 2016). As B. Q. Liu (2016) proposed, increased student interaction in SCs may include pushing learning resources (e.g., videos, activities, quiz) and providing feedback, oral communication, timely feedback, personalised teaching, homework management and evaluation. Y.-L. Li (2019) further classified the interaction in SCs into the following categories:

- teacher-student interaction (organisation and management, question and answer, guidance and inspiration, guidance and answering, communication and discussion, evaluation and feedback, request and answer)

- $\quad$ student-student interaction (question answer, communication cooperation, evaluation feedback)

- teacher-media interaction (teacher manipulate technology)

- $\quad$ student-media interaction (technology works on students, student manipulation technology).

Specifically, we consider that personalised resource pushing, the tracking of students' learning process and timely evaluation are unique to SCs and not easily achieved in TMCs. 
SCs use smart terminals and mobile learning tools and platforms to support communication between teacher and students (B. Q. Liu, 2016; MacLeod et al., 2018), which might be the fundamental difference distinguishing SCs from TMCs. Generally, in TMCs, teachers need to rely on their teaching experience and intuition to judge students' learning status and carry out the teaching accordingly, while in SCs, teachers can more accurately and quickly analyse students' learning status based on smart terminals and learning analytics (X.-R. Wu et al., 2019; Zhao, 2017) and adjust the teaching process based on their understanding of students' needs (Chen, 2020; L. Li et al., 2018). For example, the resource platform in SCs can store structured learning materials and record the students' use log data, which helps to illustrate learning status (Zhai et al., 2016). Also, SCs can expand the learning space by providing online homework, online questions and answers and learning resource recommendations (Xi et al., 2017). In addition, the teaching response system can be used to collect student feedback on exercises during class (H. M. Li \& Zhang, 2015), resulting in more precise and convenient interactions.

In short, SCs and TMCs are equipped with different features, which engender different teaching and learning methods. However, comparisons between teacher-student interaction across classroom environments, especially at the level of behavioural sequence, is limited in the literature. Therefore, this research sought to find out whether classroom environments (SC versus TMC) affect the behaviours of teachers and students and their interaction patterns, in order to obtain more insights into the influence of the SC environment on shifting teacher-student interaction patterns. The following question guided this research: Is there any difference in teacher and student behaviours and their behavioural sequence patterns between SCs and TMCs?

\section{Methods}

\section{Participants}

Twenty in-classroom teaching sessions were randomly selected from six universities in South China, involving a total of 1,043 students and teachers. Ten sessions taken in SCs were chosen as the experimental group, which covered a wide range of subject matter (Chinese, English, mathematics, physics, biology). Ten sessions with same course content taught in TMCs and served as the control group. Each session lasted for about 40 minutes. All the organisations in this study had been using SCs for 1.5 years; thus, the teachers and students were already familiar with the SC environment and could skillfully operate the hardware and software equipment. We informed all the participants that we were recording the class and asked for their consent. All of them were aware that their behaviours were being analysed and that the data they provided would be anonymous.

\section{Procedure}

This study compared teacher-student interaction in SCs and TMCs by using behavioural analysis and lag sequential analysis (LSA; Sackett, 1978). First of all, we recorded the in-classroom videos and generated class logs in both SC and TMC groups. Secondly, two of us coded the videos every 3 seconds using a selfdeveloped coding scheme that synthesised the existing in-classroom interactive behavioral analysis framework (Gu \& Wang, 2004; Han et al., 2015; Luo et al., 2019; Zhan et al., 2020; Zhang et al., 2016), resulting in a total of 17,805 pieces of behavioural codes. Thirdly, we conducted descriptive statistics on the proportion of teacher and student talk and activities and used $t$ test to analyse the behavioural difference between TMC and SC groups. Finally, we adopted LSA to develop the behavioural transition diagram and visualise the differences in teacher-student interaction across the classroom environments.

\section{Behavioural coding}

There are several options when we choose the coding schema for teacher-student interaction analysis. Inclassroom student-teacher analysis is generally used; it analyses from two dimensions (i.e., teacher behaviours and non-teacher behaviours) and calculates the proportion of behaviours in class. However, student-teacher analysis does not classify teacher and student behaviours into meaningful clusters, and it is difficult to illustrate the entire in-classroom teaching process (Han, 2015). The Flands interaction analysis system is another coding schema that is frequently used to observe teacher-student behaviour (Flanders, 1963). However, it emphasises the verbal interaction of teachers and students, while neglecting non-verbal interaction and the impact of technology. Subsequently, some scholars have improved the Flands 
interaction analysis system. For example, Gu and Wang (2004) enriched the coding schema by adding dimensions of "students' talk" (p. 19) and "the interaction between people and technology" (p. 19) (e.g., teacher manipulation technology, student manipulation technology, technology acts on students). However, there is no further specific classification of people-technology interaction; and thus, it is not sufficient for discussing the impact of technology on human interaction. Mu and Zuo (2015) designed a teaching behaviour analysis system based on coding teaching activities and classified the in-classroom application of technology into teacher activities and student activities. However, the system does not consider the motivation or the driver of the initiator of the behaviours.

This study synthesised the existing in-classroom interactive behavioural analysis framework (Gu \& Wang, 2004; Han et al., 2015; Luo et al., 2019; Zhan et al., 2020; Zhang et al., 2016) and developed a coding schema to fully represent all the interactions between teachers and students. In classroom behaviour analysis, it is important to observe the behaviours of students and teachers separately, which is helpful for summarising behavioural features (Brandmiller et al., in press) and deducting the causal relationship between the teacher's and the students' behaviours (Pakarinen et al., 2014). Based on the existing frameworks, the in-classroom teaching and learning behaviours were classified into four dimensions, namely, teacher-talk, teacher-action, student-talk and student-action, which formed the first-level coding categories in the coding schema, as described below:

- The teacher-talk dimension is specifically divided into instructing, questioning, guiding, feedback, task-arranging (Han et al., 2015; Luo et al., 2019), classroom supervision and control (e.g., warning students and managing order) (Mu \& Zuo, 2015).

- The teacher-action dimension is generally divided into observation, listening, testing, manipulate technology (Gu \& Wang, 2004), teachers participating in students' activities (Zhang et al., 2016).

- The student-talk dimension includes asking question, discussion, answer question, reading, group activities (Luo et al., 2019; Zhang et al., 2016).

- The student-action dimension generally includes observation, listening, doing exercise, taking notes, thinking, creating works, manipulate technology, helpless and confused, doing experiments (Han et al., 2015; Zhang et al, 2016), students responding to teachers' management guidance (Luo et al., 2019).

In our coding schema, each behaviour could be distinguished as teacher-initiated or student-initiated. Teacher-initiated behaviours were generally dominated by the teacher's teaching, and the students' corresponding behaviours were the follow-up actions (e.g., teachers systematically summarise course content and ask questions, students listen and think). Student-initiated behaviours were generally dominated by students' learning, and the teacher plays the role as a guide and keeping students on track (Y. Wang \& Suo, 2020). This classification is supported by Flands interaction analysis system, which divides studenttalk into teacher-driven and student-initiated, in order to analyse the effect of the teacher's behaviour on students' learning attitude and achievement. Starting with the Flands interaction analysis system system, Feng et al. (2016) added student active questioning, distinguishing between students' active response and passive response, so as to observe students' enthusiasm for participating in class activities, which we also considered in our study.

To sum up, this study synthesised the existing in-classroom interactive behavioural analysis framework (Gu \& Wang, 2004; Han et al., 2015; Luo et al., 2019; Zhan et al., 2020; Zhang et al., 2016) to develop a teacher-student interaction coding schema, as shown in Table 1. The coding schema generally divides behaviours into four themes, namely teacher-talk, teacher-action, student-talk and student-action and whether initiated by the teacher or by the students, which helps to understand how SC environments help to improve learning motivation. 
Table 1

Teacher-student interaction coding schema

\begin{tabular}{|c|c|c|c|c|}
\hline Participant & Type of behaviour & Initiatied vs. driven & Description & Code \\
\hline \multirow[t]{6}{*}{ Teacher } & Talk & Teacher-initiated & Instructing & TI \\
\hline & & Teacher-initiated & Questioning & TQ \\
\hline & & Teacher-initiated & Managing & TM \\
\hline & & Teacher-initiated & Task-arranging & $\mathrm{TT}$ \\
\hline & & Student-driven & Guiding & SG \\
\hline & & Student-driven & Feedback & SF \\
\hline \multirow[t]{5}{*}{ Teacher } & Action & Teacher-initiated & Observation & TO \\
\hline & & Teacher-initiated & Listening & $\mathrm{TL}$ \\
\hline & & Teacher-initiated & Testing & $\mathrm{TST}$ \\
\hline & & Teacher-initiated & Manipulate technology & TMT \\
\hline & & Student-driven & Join students' activity & SJ \\
\hline \multirow[t]{5}{*}{ Student } & Talk & Teacher-driven & Answer question & TAQ \\
\hline & & Teacher-driven & Reading & $\mathrm{TR}$ \\
\hline & & Teacher-driven & Group activities & $\mathrm{TG}$ \\
\hline & & Student-initiated & Ask question & SAQ \\
\hline & & Student-initiated & Discussion & $\mathrm{SD}$ \\
\hline \multirow[t]{10}{*}{ Student } & Action & Student-initiated & Observation & $\mathrm{SO}$ \\
\hline & & Student-initiated & Listening & SL \\
\hline & & Student-initiated & Taking notes & STN \\
\hline & & Student-initiated & Doing experiments & SDE \\
\hline & & Student-initiated & Thinking & ST \\
\hline & & Student-initiated & Creating works & SCW \\
\hline & & Student-initiated & Manipulate technology & SMT \\
\hline & & Student-initiated & Helpless and confused & $\mathrm{SHC}$ \\
\hline & & Teacher-driven & Doing exercise & TDE \\
\hline & & Teacher-driven & $\begin{array}{l}\text { Following teachers' } \\
\text { management guidance }\end{array}$ & TFM \\
\hline
\end{tabular}

During the coding processes, two of us coded the collected behaviours independently. The level of agreement between us is represented by a Cohen's kappa coefficient of 0.8907 , indicating a sufficiently high reliability in the coding process.

\section{LSA}

LSA is a method of behaviour analysis proposed by Sackett (1978) and has been widely used in various fields. In educational research, it helps to analyse the frequency of related behaviours recorded in the learning process, digs out significant behaviour sequences, and analyses the behaviour characteristics, the factors driving the behaviour and other valuable information (Bakeman \& Gottman, 1997). For example, S.-Y. Wu and Hou (2015) used LSA to explore how cognitive styles affect online discussion behaviours during the problem-solving process. Lamsa et al. (2020) combined log data and LSA to investigate temporal differences between scaffolded and non-scaffolded group inquiry-based learning processes. In this study, LSA was used to analyse and visualise the observed changes in teacher-student interaction patterns in SCS and TMCs. It was conducted in three steps: First, the number of transitions between any two behaviours was counted. Subsequently, the behaviour sequences were screened out by adjusted residuals ( $z$ scores). The residuals indicate whether the observed frequency of the behaviour pattern deviates from its expected value, and the adjusted residuals help to transform the behavioural sequence data of different magnitudes into the same magnitude to ensure that different behavioural sequences are comparable. The pair of behaviours with an adjusted $z$ score higher than $1.96(p<0.05)$ are recognised as having a significant sequential relationship. The operation of calculating a $z$ score can be carried out with General Sequential Querier 5.1. Finally, a behavioural transfer diagram of the statistically significant sequential relationships was drawn and analysed. 


\section{Results}

\section{Teacher and student behaviours in SCs and TMCs}

Figure 1 presents the frequency of behavioural categories in SCs and TMCs. As can be seen, student-driven teacher-talk, student-initiated talk, teacher- and student-initiated actions all increased in the SCs, while teacher-initiated talk decreased significantly. $T$ test results indicate that teacher-initiated talk in the SCs was significantly less than that in the TMCs $(t=-2.994, p=0.008<0.01)$, while teacher-initiated actions in the SCs were significantly more than in the TMCs $(t=3.216, p=0.005<0.01)$, indicating that teacherinitiated talk led to student-driven talk in the smart environment, while teacher-driven student-talk was not changed significantly.

Furthermore, the frequency of student-driven teacher-action, student-initiated talk and teacher-driven student-talk showed no significant difference between the SCs and TMCs. Comparing the total number of teacher-dominated or student-dominated behaviours, teacher-initiated talk decreased by $9.38 \%$ in the SCs, while the proportion of student-driven teacher-talk increased correspondingly. In terms of student-talk, the proportion of student-initiated talk increased by $3.09 \%$, and student-initiated actions increased by $2.32 \%$, indicating that students' dominant position is enhanced in SCs.

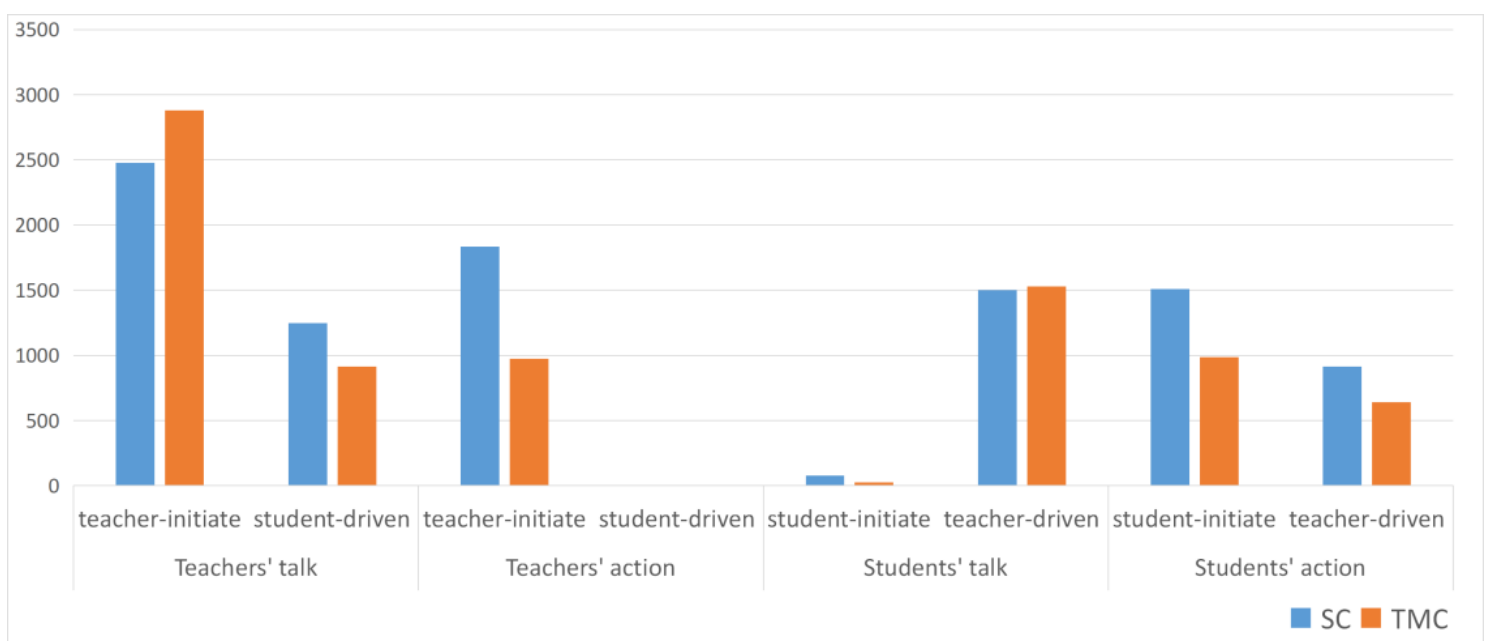

Figure 1. Frequency of behavioural categories in SCs and TMCs

Figure 2 shows the specific behaviour coding frequency in the SCs and TMCs. Compared to TMCs, some behaviours, such as teacher instruction behaviour (TI), student observation behaviour (SO) and student listening behaviour (SL), were greatly reduced in the SCs, while teacher use technology (TMT), student ask question (SAQ), student thinking (ST) and students manipulate technology (SMT) increased significantly. A $t$ test was further conducted on the behavioural frequencies; the results indicate that among these 26 behaviours, 6 of them had significant differences between the SCs and TMCs: teacher instruction behaviour (TI) was significantly higher in the TMCs $(t=-2.576, p=0.019<0.05)$, while teacher guiding behaviour (SG) $(t=2.515, p=0.022<0.05)$, teacher testing behaviour (TST) $(t=2.006, p=0.006<$ $0.05)$, teacher manipulating technology (TMT) $(t=4.175, p=0.001<0.05)$, student thinking behaviour (ST) $(t=2.466, p=0.019<0.024)$ and student manipulate technology behaviour (SMT) $(t=4.031, p=$ $0.001<0.05)$ were all significantly higher in the SCs. 


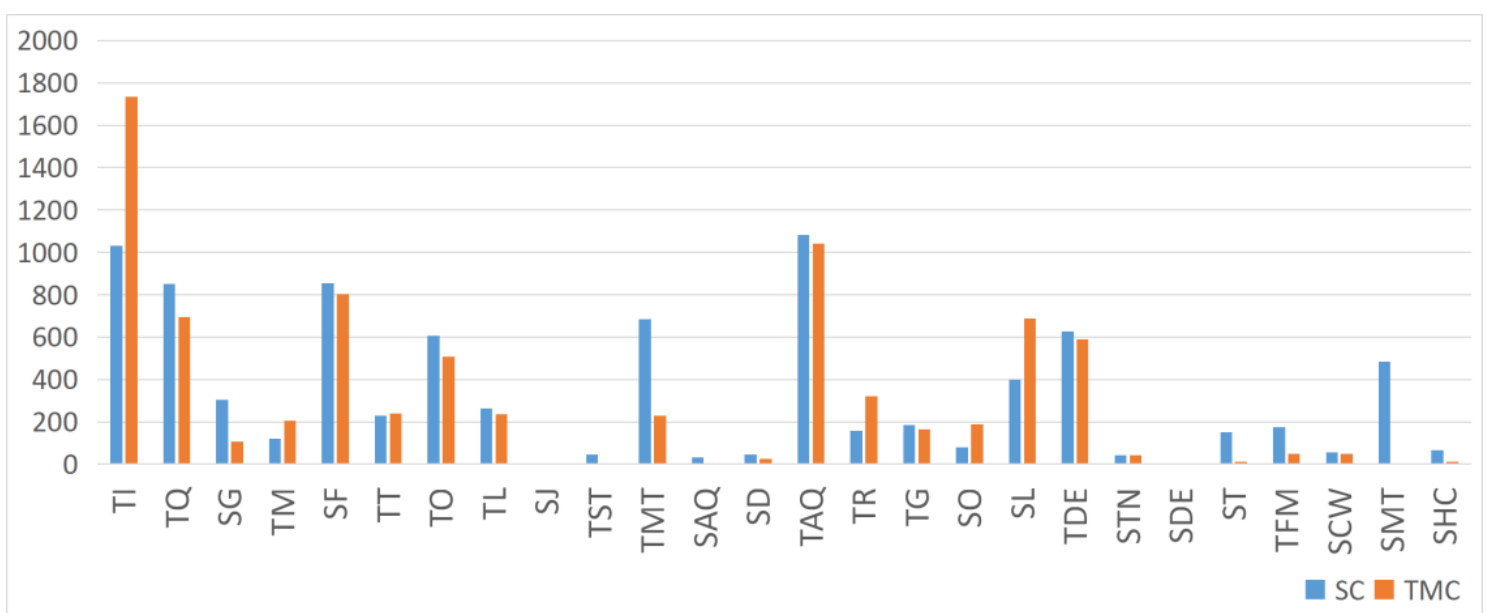

Figure 2. Frequency of behaviours in SCs and TMCs

\section{Teacher and student behavioural sequence patterns in SCs and TMCs}

Figure 3 shows the behavioural sequence patterns in SCs and TMCs, where each node represents one type of behaviour from the coding table. According to the $z$ value calculated by General Sequential Querier 5.1, Figure 3 presents the significant behavioural sequence conversion diagram drawn in accordance with the subsequent rules:

- The four sides represent teacher language, teacher activity, student language and student activity respectively.

- The first letter of each code represents the agent driving the behaviour (e.g., "T" indicates that the behaviour was driven by the teacher; " $S$ " indicates that the behaviour was driven by student).

- The thickness of the line indicates the significance of the behaviour sequence (the larger the adjusted $z$ value, the thicker the line). As can be seen, the behaviour conversion network displayed in the SCs was more abundant and connected than that in the TMCs. Remarkably, the behaviour of teachers giving feedback (SF), teachers task arranging (TT), students asking questions (SAQ), students doing exercise (TDE), students manipulating technology (SMT), students creating works (SCW) and teachers manipulating technology (TMT) indicate that students engaged in practical activities with technologies more frequently, and their self-generated behaviours in SCs was greater, suggesting that diversified teaching activities enhance interaction.

As can be seen in Figure 3, the teacher-driven behaviours are the main cause of teacher-student interaction in TMCs, while in SCs, student-initiated behaviour increased a lot. For example, in the TMCs, the sequence of behaviour conversion with the largest adjusted $z$ value consisted of teacher observe students doing exercises (TDE-TO), students observing or listening carefully while teachers giving lectures by using smart technology (TI-SL, TI-TMT-SO), students answering questions and teacher listening to it (TAQ-TL) and teacher managing students' reading activity (TFM-TR). Other than that, more significant sequences occurred in the SCs, such as students doing exercises with smart technology (TDE-SMT), teacher observe students using technology (SMT-TO) and teacher guiding students' discussion (SD-SG). 


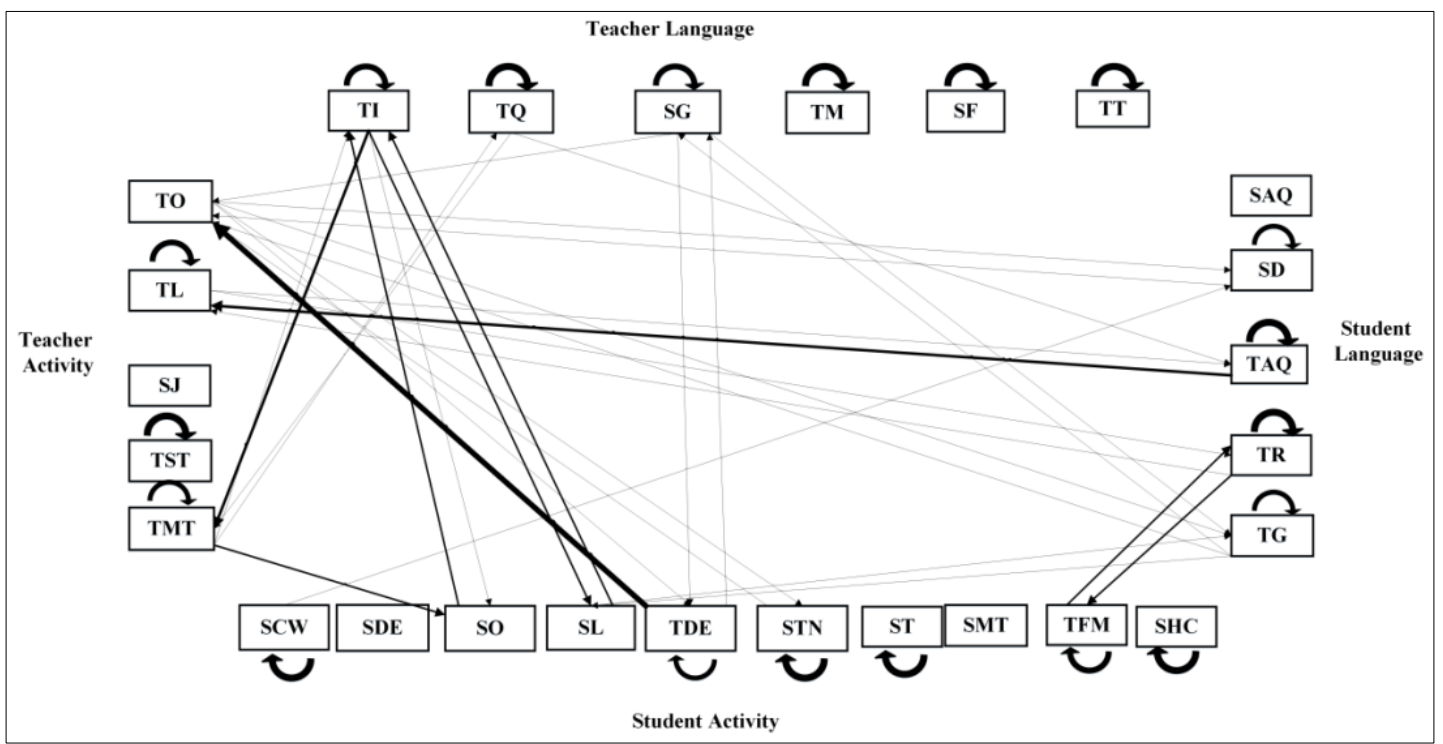

(a) Teacher-student behaviour pattern in TMCs

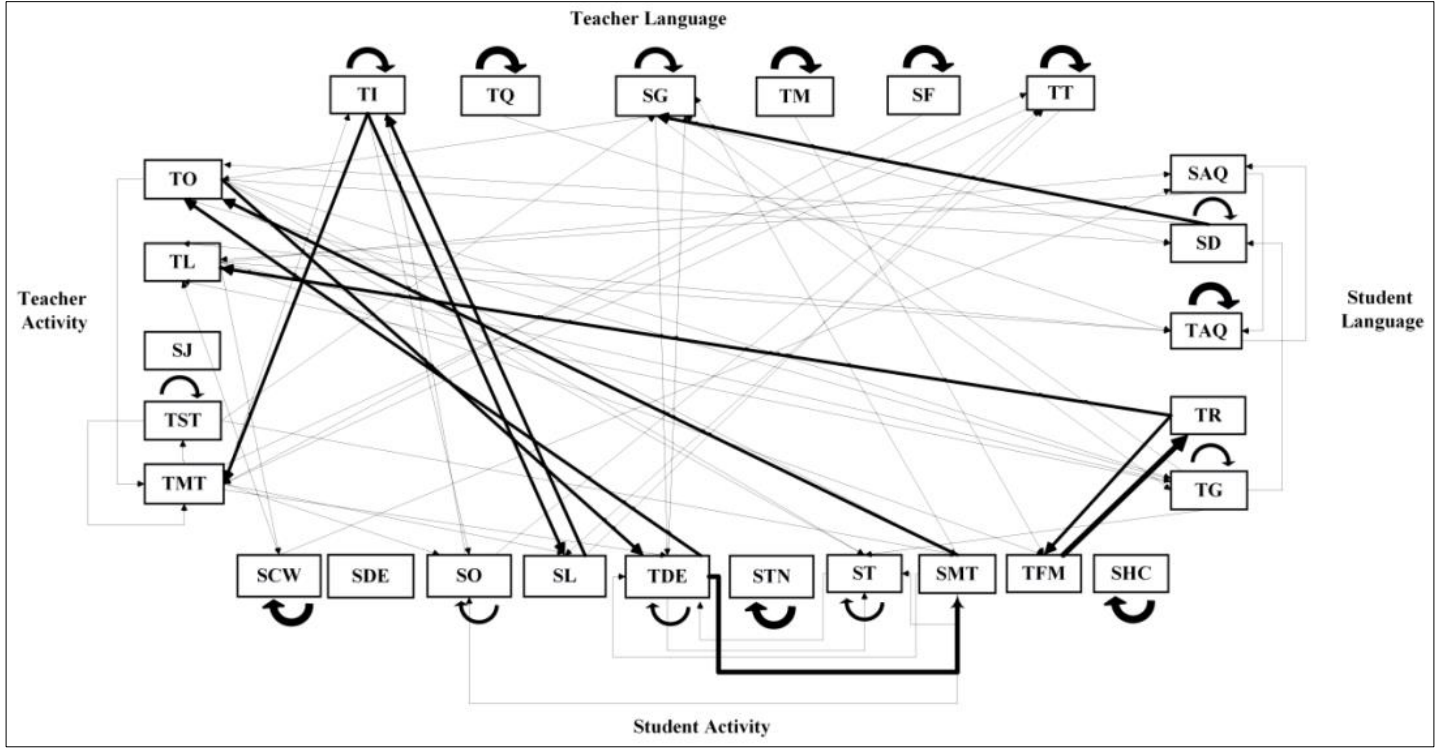

(b) Teacher-student behaviour pattern in SCs

Figure 3. Significant behaviour patterns in TMCs and SCs

To explore the impact of smart technology in teaching and learning, we observed the conversion started from teacher manipulating technology (TMT) and students manipulating technology (SMT). In the TMCs, only the interaction between teachers and technology led to significant subsequent student behaviours. Furthermore, the teachers' use of technology generally took place in teacher teaching (e.g., TMT-TI), teacher questioning (e.g., TMT-TQ) and guiding students to observe (e.g., TMT-SO). However, in the SCs, teachers not only used technology for teaching (TI) and questioning (TQ) but also for testing (TST), observation of student behaviour (TO), releasing task (TT), help students observe with technology (SO), thinking (ST) and assisting exercises (TDE- SMT).

Although the significant self-circulation behaviour sequences in the SCs and TMCs were mostly the same, there was a great proportion of silent behaviours on the part of the students. It might be worth exploring the factors that cause students' helpless and confused behaviours (SHC) in either TMCs or SCs. In this study, the $z$ score of SHC was larger than 1.96 both in SCs and TMCs, and the frequency of SHC in the SCs was higher than that in the TMCs. 


\section{Discussion}

\section{Talks versus actions across different classroom environments}

Talk refers to teacher and students' oral behaviours. There was no significant difference in the total number of student-talk between the SC and TMC environments; however, the frequency of students asking questions in the SCs increased, while that of teacher requiring student to read reduced. Students asked teacher questions mainly through project-based activities or by raising a question during the process of answering the teacher's questions.

Overall, teacher-talk occupied the largest proportion of the class, whether in the SC or TMC environments. However, teacher-talk reduced in the SCs, mainly because the teachers' instruction reduced, while their behaviours of proposing questions, giving feedback and providing guidance increased significantly. Students' questions resulted in the teacher giving the necessary feedback or explanation on the specific problems.

Why does teacher-initiated talk decrease in SCs? The answer can be found in the function of SCs: they help teachers save time on teaching new concepts and perceiving students' learning status. Teachers no longer need to spend a lot of time on giving lectures, but rather, they can pay more attention to helping students consolidate their knowledge, organising discussions and solving problems in the classroom. SCs also support teachers to try new pedagogies (e.g., flipped learning, problem-based learning), so that the teacher's corresponding verbal behaviours (e.g., giving feedback, questioning, guiding, explaining) and students' verbal behaviours (i.e., questioning, discussing, practising) increase.

Action refers to the specific activities without oral inputs. Compared to TMCs, students' active actions in the SCs increased significantly, including practical exercise, active thinking, creating works and manipulating technology; however, their passive actions (e.g., observation and listening) decreased. Furthermore, teachers' actions on manipulating technologies and smart testing increased significantly.

Unexpectedly, in both the SC and TMC environments, the frequency of students' helpless and confused behaviours made us reconsider the influence of technologies, in terms of their advantages and disadvantages.

On the one hand, in TMCs, multimedia technologies are beneficial for enriching the presentation of learning content, displaying information that is difficult to visually express and deepening students' understanding in abstract knowledge (L. Wang et al., 2009). On the other hand, in a technology-rich environment, teachers sometimes pay too much attention to technology, ignoring the interaction between teachers and students and the knowledge construction process between students and technology (Guo \& Zheng, 2012; X. Wang, 2011). For example, Guo and Zheng (2012) pointed out that due to the excessive emphasis on multimedia, many teachers often focus on the design of beautiful and attractive courseware, rather than the design of instruction. According to Jiang (2017), teachers need to manipulate the computer to display slides on the large screen during class; therefore, they often stand behind the main console to control the computer during class, keeping away from the students. At the same time, students need to pay close attention to the projection screen, or they look down at textbooks and take notes, which is difficult for effective studentteacher interaction. Therefore, this is one of the most important reasons for students' quiet behaviours in TMCs.

However, we found that students' helpless and confused behaviours differed between SCs and TMCs. On the one hand, teachers and students benefit from the smart technology by enriching in-classroom interactions. Teachers can use technology to visualise teaching content and display the students' assignments and work. Students can use smart technology to demonstrate and explore (Jiang et al., 2019). On the other hand, the shortcomings of smart technology are also obvious. Running equipment in SCs depends on skillful technical staff, adequate power support and stable network connections. Without these, smart technology may bring teacher and students to quietness and feelings of helplessness. For example, due to an unstable network, the all-in-one teaching machine may take a long time to connect and respond, resulting in pauses in the teaching process or confusion (Shi et al., 2019). Moreover, since teachers and students are not familiar with smart techniques, they may fail to use it properly, which also affects the normal progress of classroom activities (Jiang et al., 2019). 


\section{Teacher-driven versus student-driven behaviours across different classroom environments}

Compared to TMCs, teacher-initiated talk in SCs reduced, and student-driven teacher-talk increased, indicating that some of the teachers' spontaneous behaviours result in student-driven behaviours in an SC environment. In other words, SCs strengthen student-centered pedagogy.

Significant difference was found between student-initiated actions and teacher-driven student-actions. Although both increased in the SCs, student-initiated actions increased more rapidly. With mobile terminals, students can retrieve information and overcome problems together, which helps them save time from asking for the teacher's help and waiting for feedback. This indicates that SCs help students to learn spontaneously and collaboratively.

When comparing teacher-driven behaviours and student-driven behaviours, it is worth noting that teachers seldom actually join students' activities in person; that is, when teachers work with students in problemsolving or in creating products in project activities. However, in this study, the class size was generally big (with around 40 students per class); thus, it was difficult for teachers to participate in students' collaboration in person. Teachers normally inquire or observe the progress of each group and evaluate or provide necessary guidelines.

\section{Teacher-student interaction in SCs versus TMCs}

The findings of this study represent the major difference in teacher-student interaction between SCs and TMCs, which could be summarised as follow: First of all, the SCs add important channels for collecting information on the status of students' learning from the mobile terminals. Meanwhile, the smart technology supports teachers to find students' mistakes with less effort, which is more convenient for teachers for evaluating students' status and providing timely and effective feedback.

Second, SCs support teachers to create richer types of interactions, which is consistent with other research (Zhan, in press). Teachers can use online platforms to organise various forms of activities (e.g., quiz, games, and competitions). The platform automatically records some key information (e.g., correct rate) when students complete the test, representing their learning status, and gives more effective feedback and guidance with technical assistance to optimise the interaction process.

Third, SCs provide better ways to display teaching content. Dale's (1969) "cone of experience" emphasised experience gained through direct sensory experience and participation. Teachers use graphics and text in SCs to enrich students' observation and listening behaviours and visualise abstract content in a more intuitive way.

Fourth, SCs make classroom management more convenient and help teachers save time from trivial activities that are not conducive to teaching. For example, teachers can use the teaching management and activity arrangement function in SCs to improve and enhance the quality of activities and make the interaction more efficient.

Fifth, students also have more opportunities to manipulate technology in SCs, especially during the thinking and creating process (e.g., search resources, collaborate in groups, share assignments, conduct experiments in a virtual laboratory), which helps them gain specific learning experience through direct participation. Consequently, the proportion of students' behaviours (both talk and action) increase, while their observation and listening behaviours decrease. We also found that smart technology has a greater impact when students are learning new knowledge or abstract concepts. For example, conducting complex experiments in virtual laboratories settings in SCs can deepen students' understanding of chemical processes. 


\section{Implications and future research}

This study systematically compared the interaction of teachers and students in SC and TMC environments in higher education settings, paying special attention to their oral and behavioural activities and the potential motivation for causing the activities. We established and adopted a behavioural analysis model, then coded and analysed the behavioural sequences according to teacher-talk, teacher-action, student-talk and studentaction. Compared to TMCs, the SCs triggered significantly more student-initiated actions and studentdriven teacher-actions, indicating that the students' dominant position was significantly strengthened.

These findings deepen our understanding of how smart technologies in SCs help to improve teaching and learning, and the impacts on teacher-student interactive behaviour sequence. In light of the findings, we recommend that teachers provide proper guidance and scaffolding to support students in the smart classroom, especially during the inquiry process. Moreover, instructional designers should consider more course activities and collect students' feedback during the course via smart terminals, to make the learning process more assessable. Furthermore, university departments (e.g., centres of teacher development) should provide the necessary training to help teachers become acquainted with SC infrastructure and provide the necessary technical support during class.

This study investigated the impact of the smart technology from behavioural perspectives; thus, we suggest that future studies could investigate the impact of smart technology-enhanced environment from cognitive or emotional perspectives. For example, it would be interesting to investigate teachers' and students' attitudes towards taking a class in SCs or TMCs, so as to further explore the effect of smart technology in classroom environments and look at possible reasons for explaining our findings. In addition, we recommend a further experimental study on supporting and scaffolding strategies for improving teacherstudent interaction in smart classroom environment.

\section{Acknowledgements}

This study was supported by the Major basic research and applied research projects of Guangdong Education Department (\#2017WZDXM004), MOE (Ministry of Education in China) Project of Humanities and Social Sciences (\#19YJC880125); National Social Science Foundation of China (\#18BGL053). We also want to thank all the organisations and participants in this study.

\section{References}

Akhrif, O., Benfares, C., El bouzekri el idrissi, Y., \& Hmina, N. (2020). Collaborative approaches in smart learning environment: A case study. Procedia Computer Science, 175, 710-715. https://doi.org/10.1016/j.procs.2020.07.105

Bakeman, R., \& Gottman, J. M. (1997). Observing interaction: An introduction to sequential analysis (2nd ed.). Cambridge University Press. https://doi.org/10.1017/CBO9780511527685

Brandmiller, C., Dumont, H., \& Becker, M. (in press). Teacher perceptions of learning motivation and classroom behavior: The role of student characteristics. Contemporary Educational Psychology, 101893. https://doi.org/10.1016/j.cedpsych.2020.101893

Cai, J.-B., Xiao J., \& Lin Y. (2012). A study on the establishment of interpretation teaching model based on multi-media network. In A. Xie \& X. Huang (Eds.), Advances in computer science and education: Advances in intelligent and soft computing (Vol. 140, pp. 377-383). Springer. https://doi.org/10.1007/978-3-642-27945-4_60

Chen, X.-Y. (2020). On the interactive strategies of smart classroom teaching from the perspective of value co-creation theory. Contemporary Education Research and Teaching Practice, 5, 3-4. https://doi.org/10.16534/j.cnki.cn13-9000/g.2020.0487

Dale, E. (1969). Audiovisual methods in teaching (3rd ed.). Holt, Rinehart and Winston.

Feng, Z.-H., Wu, W.-C., \& Hu, X.-Y. (2016). 面向翻转课堂的课堂互动分析编码研究 (Research on the coding of classroom interaction analysis in the flipped classroom). Journal of Distance Education, 34(04), 59-64. https://doi.org/10.15881/j.cnki.cn33-1304/g4.2016.04.008

Flanders, N. A. (1963). Intent, action and feedback: A preparation for teaching. Journal of Teacher Education, 14(3), 251-260. https://doi.org/10.1177/002248716301400305 
Fu, J. (2011). 高校多媒体教学的现状分析与思考 (Analysis and thinking on the status quo of multimedia teaching in universities). Jiangsu Higher Education, 1, 88-89. https://doi.org/10.13236/j.cnki.jshe.2011.01.057

$\mathrm{Fu}$, S.-H. (2019). 交互式多媒体环境下小学数学教与学方式变革 (The reform of primary school mathematics teaching and learning in interactive multimedia environment). Educational Practice and Research, 12, 29-30. https://doi.org/10.14160/j.cnki.13-1259/g4-a.2019.12.010

Gu, X.-Q., \& Wang, W. (2004). 支持教师专业发展的课堂分析技术新探索 (Support teachers' development with IT-based interaction analysis system in class). China Educational Technology, 7, 18-21. https://doi.org/10.3969/j.issn.1006-9860.2004.07.004

Guo J., \& Zheng J. (2012). Research on application of multimedia teaching over literature classroom. In W. Zhang (Ed.), Advanced technology in teaching: Advances in intelligent and soft computing (Vol. 163, pp. 465-471). Springer. https://doi.org/10.1007/978-3-642-29458-7 69

Hamiti, M., \& Reka, B. (2012). Teaching with technology. Procedia - Social and Behavioral Sciences, 46, 1171-1176. https://doi.org/10.1016/j.sbspro.2012.05.269

Han, H., Wang, D.-Q., \& Cao, C. (2015). 1:1数字化环境下课堂教学互动行为的分析研究 (1:1 Analysis and research on classroom teaching interaction behavior in digital environment). e-Education Research, 36(5), 89-95. https://doi.org/10.13811/j.cnki.eer.2015.05.013

Huang, R.-H., Hu, Y.-B., Yang, J.-F., \& Xiao, G.-D. (2012). The functions of smart classroom in smart learning age. The Journal of Open Education Research, 18(2), 22-27. https://doi.org/10.3969/j.issn.1007-2179.2012.02.004

Jia, X.-B., Chai, W.-X., \& Zhao, E.-P. (2014). 多媒体教学的优缺点及应对措施研究 (Research on the advantages and disadvantages of multimedia teaching and countermeasures). China Electric Power Education, 32, 26-27. https://doi.org/10.19429/j.cnki.cn11-3776/g4.2014.32.012

Jian, H.-S., \& Hong, L. (2012). Explore the effective use of multimedia technology in college physics teaching. Energy Procedia, 17, 1897-1900. https://doi.org/10.1016/j.egypro.2012.02.329

Jiang, Y. (2017). 多媒体智慧教室建设解决方案 (Multimedia smart classroom construction solution). Science \& Technology Information, 15(14), 133-134. https://doi.org/10.16661/j.cnki.1672$\underline{3791.2017 .14 .133}$

Jiang, Y., Wang, W., Li, C.-Y., Kang, M.-M., \& Shen, J. (2019). 智慧教室环境下师生互动行为研 (An analysis of teacher-student interaction in the smart classroom). Modern Distance Education, 3, 13-21. https://doi.org/10.13927/j.cnki.yuan.2019.0023

Jin, N., Yang, F., Yan, M., Feng, Y., Zhuang, Y., Liu, H., \& Wen, K. (2019). User perceptions of smart class services in teaching and learning interactions. Procedia CIRP, 83, 785-788. https://doi.org/10.1016/j.procir.2019.04.329

Kong, X.-R. (2018). 互联网+时代基于物联网云计算构建智能教学环境设计与实现 (Design and implementation of intelligent teaching environment based on Internet of Things cloud computing in Internet era). Computer Knowledge and Technology, 14(29), 269-271. https://doi.org/10.14004/j.cnki.ckt.2018.3476

Lamsa, J., Hamalainen, R., Koskinen, P., Viiri, J., \& Mannonen, J. (2020). The potential of temporal analysis: Combining log data and lag sequential analysis to investigate temporal differences between scaffolded and non-scaffolded group inquiry-based learning processes. Computers \& Education, 143. https://doi.org/10.1016/j.compedu.2019.103674

Li, H.-M., \& Zhang, J.-P. (2015). The ARS interactive teaching model and its application in the smart classroom. China Educational Technology, 11, 103-109. https://doi.org/10.3969/j.issn.1006$\underline{9860.2015 .11 .015}$

Li, L., Liang, W.-J., \& Xue, F. (2018). 智慧教室环境中的课堂互动教学现状分析一基于小学数学课 堂教学个案的研究 (Analysis of classroom interaction in smart classroom: A case study of math lesson at primary school). e-Education Research, 39(3),115-121. https://doi.org/10.13811/j.cnki.eer.2018.03.018

Li, Y.-L. (2019). 基于智慧教室环境的小学数学课堂教学互动行为特征的分析 (Characteristic analysis of interaction behavior of mathematics teaching in elementary schools under smart classroom environment). Survey of Education, 8(11),112-113. https://doi.org/10.16070/j.cnki.cn45$1388 / \mathrm{g} 4 \mathrm{~s} .2019 .11 .050$

Liu, B. Q. (2016). “互联网+”时代智慧课堂教学设计与实施策略研究 (Research on design and implementation strategy of smart class teaching in the era of "Internet +"). China Educational Technology, 10, 51-56,73. http://dx.chinadoi.cn/10.3969/j.issn.1006-9860.2016.10.009 
Liu, J., Jiang, J., \& Li, X. D. (2009). 多媒體課堂教學低效歸因的分析 (Analysis of the inefficient attribution of multimedia classroom teaching). Heilongjiang Researches on Higher Education, 12, 185-187. http://dx.chinadoi.cn/10.3969/j.issn.1003-2614.2009.12.062

Luo, Z.-Y., Lu, J., Zhang, D.-H., \& Li, D.-X. (2019). A teaching scene coding method based on classroom log (Chinese Patent, CN109284390A). China National Intellectual Property Administration.

MacLeod, J., Yang, H.-H., Zhu, S., \& Li, Y. (2018). Understanding students' preferences toward the smart classroom learning environment: Development and validation of an instrument. Computers \& Education, 122, 80-91. https://doi.org/10.1016/j.compedu.2018.03.015

Mu, S., \& Zuo, P.-P. (2015). 信息化教学环境下课堂教学行为分析方法的研究 (Research on the method of classroom teaching behavior analysis under the information-based teaching environment). e-Education Research, 36(9), 62-69. https://doi.org/10.13811/j.cnki.eer.2015.09.011

Pakarinen, E., Aunola, K., Kiuru, N., Lerkkanen, M.K., Poikkeus, A.M., Siekkinen, M., \& Nurmi, J. E. (2014). The cross-lagged associations between classroom interactions and children's achievement behaviors. Contemporary Educational Psychology, 39(3), 248-261. https://doi.org/10.1016/j.cedpsych.2014.06.001

Rusanganwa, J. (2013). Multimedia as a means to enhance teaching technical vocabulary to physics undergraduates in Rwanda. English for Specific Purposes, 32(1), 36-44. https://doi.org/10.1016/j.esp.2012.07.002

Sackett, G. P. (1978). Observing behavior: Theory and applications in mental retardation (Vol. 1). University Park Press.

Selim, H. M., Eid, R., \& Agag, G. (2020). Understanding the role of technological factors and external pressures in smart classroom adoption. Education + Training, 62(6), 631-644. https://doi.org/10.1108/ET-03-2020-0049

Shah, S. A. (2013). Making the teacher relevant and effective in a technology-led teaching and learning environment. Procedia - Social and Behavioral Sciences, 103, 612-620. https://doi.org/10.1016/j.sbspro.2013.10.379

Simelane, S., \& Mji, A. (2014). Impact of technology-engagement teaching strategy with the aid of clickers on student's learning style. Procedia - Social and Behavioral Sciences, 136, 511-521. https://doi.org/10.1016/j.sbspro.2014.05.367

Shi, Y.-H., Peng, C.-L., Zhang, J.-M., \& Yang, H. (2019). 智慧教室環境下的高校師生互動行為分析 (Research on the teacher-student interaction behavior in colleges and universities under smart classroom environment). Modern Educational Technology, 29(1), 45-51. https://doi.org/10.3969/j.issn.1009-8097.2019.01.007

Wang, L., Zhang, J.-S., Gao, G.-Y., \& Xu, E.-Q. (2009). 浅谈多媒体课堂教学中的互动 (On the interaction in multimedia classroom teaching). e-Education Research, 36(9), 62-69. https://kns.cnki.net/kcms/detail/detail.aspx?dbcode=CJFD\&dbname=CJFD2009\&filename $=$ DHJY200 909025\&v=IXIsygEuos5S7iWcGg87jplgrTW2bn\%25mmd2FnHIJ3p19Yj1pwxWxN3Hni3GcnOyVp $\underline{5 p w}$

Wang, X. (2011). On how to efficiently carry out multi-media teaching. In Y. Wang (Ed.), Education management, education theory and education application: Advances in intelligent and soft computing (Vol 109, pp. 319-323). Springer. https://doi.org/10.1007/978-3-642-24772-9 47

Wang, Y., \& Suo, C.-Q. (2020). 教师自主支持对学生自主学习行为的影响一基于自我决定理论视角 (The influence of teacher autonomous support on students' autonomous learning behavior based on the perspective of self-determination theory). Journal of Educational Development, 3, 30-36. https://doi.org/10.16215/j.cnki.cn44-1371/g4.2020.03.005

Wu, S.-Y., \& Hou, H.-T. (2015). How cognitive styles affect the learning behaviors of online problemsolving based discussion activity: A lag sequential analysis. Journal of Educational Computing Research, 52(2), 277-298. https://doi.org/10.1177/0735633115571307

Wu, X.-R., Liu, B.-Q., \& Yuan, T.-T. (2019). 新一代智慧課堂:概念、平臺及體系架構 (A new generation of smart class: Concept, platform and system architecture). China Educational Technology, 3, 81-88. https://doi.org/10.3969/j.issn.1006-9860.2019.03.011

Xi, H.-X., Liao, H.-J., \& Huang, C.-G. (2017). 智慧学习环境的架构设计与实施策略 (Study on framework design and implementation strategies of smart learning environment). e-Education Research, 38(4), 72-76. https://doi.org/10.13811/j.cnki.eer.2017.04.011 
Zhai, X.-M., Sun, W., Guo, Y.-Y., \& Zhang, M.-L. (2016). 智慧教室: 應用現狀及其影響研究*--基于 高中物理學科學習的跟路研究 (Smart classroom: An evaluation of its implementations and impacts: Based on the longitude data of physics learning in a high school). China Educational Technology, 9, 121-127. https://doi.org/10.3969/j.issn.1006-9860.2016.09.019

Zhan, Z., Wu, Q., He, W., Cheng, S., Lu, J., \& Han, Y. (in press). K12 teacher-student interaction patterns in the smart classrooms. International Journal of Innovation and Learning. https://www.inderscience.com/info/ingeneral/forthcoming.php?jcode=ijil

Zhang, Y., Zhu, Y., Bai, Q.-Y., Li, X.-Y. \& Zhu, Y.-H. (2016). 智慧教室環境下小學數學課堂教學互 動行為特征研究 (Study on interactive behavior characteristics of primary school mathematics teaching in smart classroom environment). e-Education Research, 6, 43-48. https://doi.org/10.3969/j.issn.1006-9860.2016.06.009

Zhao, P.-P. (2017). 智慧课堂:优化与创新传统课堂 (Wisdom classroom: Optimization and innovation of traditional classroom). Education Modernization, 4(14),171-174. https://doi.org/10.16541/j.cnki.2095-8420.2017.14.059

Zhu, Z.-M., Xu, F.-Q., \& Gao, X. (2020). Research on school intelligent classroom management system based on Internet of Things. Procedia Computer Science, 166, 144-149. https://doi.org/10.1016/j.procs.2020.02.037

Corresponding author: Zehui Zhan, zhanzehui@m.scnu.edu.cn

Copyright: Articles published in the Australasian Journal of Educational Technology (AJET) are available under Creative Commons Attribution Non-Commercial No Derivatives Licence (CC BY-NC-ND 4.0). Authors retain copyright in their work and grant AJET right of first publication under CC BY-NC-ND 4.0.

Please cite as: Zhan, Z., Wu, Q., Lin, Z., \& Cai, J. (2021). Smart classroom environments affect teacherstudent interaction: Evidence from a behavioural sequence analysis. Australasian Journal of Educational Technology, 37(2), 96-109. https://doi.org/10.14742/ajet.6523 